\title{
SOBRE EL PATRIARCAT *
}

\author{
Veronica Beechey \\ (Universitat de Warwick)
}

En aquest article Veronica Beechey planteja l'examen d'una selecció de textos feministes sobre el patriarcat (entre altres les contribucions de Kate Millett, Sheila Jeffreys, McKenzie, etc.), analitzant també la conceptualització dualista de la societat implícita en aquests textos (sistema classe econòmica versus sistema classe sexual; mode de producció familiar versus mode de producció industrial, etc.). Beechey fa també referència als pro blemes que es presenten quan el patriatcat i el capitalisme són tractats com a estructures diferents (per exemple, ús de diferents conceptes de reproducció; separació del patriarcat d'altres aspectes del mode de producció; el fet que tot mode de producció suposa producció i reproducció; etc.). Després d'una extensa i profunda anàlisi crítica dels diferents usos que del concepte patriarcal han fet diferents teòrics (Mitchell i els sistemes de parentiu; Hartman i la dominació masclista; Eisenstein i la jerarquia sexual; etcètera), l'autora apunta que caldria concretar una teoria especiffica del patriarcat $i$ investigar les formes de patriarcat que existeixen en les institucions socials concretes.

* Les idees contingudes en aquest atticle foren concebudes en ocasió de dues conferències que vaig donar, la primera a la Universitat Comunista de Londres, el 1977, i la segona pet a Feminist Review et 1978. Bea Campbell i altres membres del Collectiu de la Feminist Review em petsuadiren perquè les escrivís coherentment, i pex tant eis haig de donar les gràcies pel seu encoratjament i suport. A més, Sally Alexander, Collen Chesterman, Simon Clarke, el Collectiu de la Feminist Review, Simon Frith, Stuart Hail, Richard Hyman, Terry Lovell i Barbara Taylor em feren comentaris sobre el primer esborrany que m’han resultat molt útils. Estic agraida a tots ells pel temps que bi esmerçaren i també a Michèle Barrett i Elizabeth Wilson per la seva ajuda en ei manuscrit final. La versió catalana d'aquest article és de Lluís Flaquer. 
El concepte de patriarcat ha estat utilitzat dins el moviment feminista per tal d'analitzat els principis en què es basa l'opressió de les dones. El concepte en si no és nou.' Té una històtia dins el pensament feminista, ja que fou usat per les primeres feministes com Virginia Woolf, el Grup de Dones Fabià i Vera Brittain, per exemple. També fou emprat pel sociòleg antimarxista Max Weber (Weber, 1968). En tractar de fer una avaluació crírica d'alguns dels usos del concepte de patriarcat en el discurs feminista contemporani, convé fer avinent les menes principals de problemes que ha intentat de resoldre. Des del punt de vista polític les feministes d'una gran varietat de tendències diferents s'han emparat del concepte de patriarcat a la tecerca d'una explicació dels sentiments d'opressió i subordinació $i$ en un desig de transformar el sentiment de rebelitó en una pràctica i una teoria polítiques. Teòricament el concepte de patriarcat ha estat utilitzat per tal de fer front a la qüestió de la base real de la subordinació de les dones i d'analitzar les formes particulars que adopta. Així, la teoria del patriarcat tracta de penetrar per sota de les experiències i manifestacions particulars de l'opressió de la dona i de formular una teoria coherent de la base de la subordinació que els dóna suport.

La noció de patriarcat que ha estat elaborada en els escrits feministes no constitueix un concepte únic o simple, sinó que té tota una varietat de significats diferents. Al nivell més general, hom ha emprat el patriarcat per referir-se a la dominació masculina i a les relacions de poder mitjançant les quals eis homes dominen les dones (Millett, 1969). A diferència de les autores feministes radicals com Kate Millett, que s'han concentrat únicament sobre el sistema de dominació masculina i subordinació femenina, les feministes marxistes han intentat d'analitzar la relació entre la subordinació de les dones i l'organització dels diversos modes de producció. De fet, el concepte de patriarcat ha estat adoptat per les feministes marxistes en un

1. Estic agraïda a Sally Alexander per les dades que em va donar sobre la història del concepte en la literatura feminista. 
intent de transformat la teoria marxista per tal que pugui explicar més adequadament la subordinació de la dona, així com les formes d'explotació de classe.

Dins de la literatura feminista marxista podem discernir diversos usos del concepte de patriarcat. Per a posar alguns exemples: Juliet Mitchell (1974) empra aquest concepte pet a referir-se als sistemes de parentiu en els quals els homes bescanvien dones, al poder simbòlic que els pares tenen dins aquests sistemes $\mathrm{i}$ a les consequèències d'aquest poder per a la «psicologia... inferioritzada de les dones» (Mitchell, 1974: 402). Heidi Hartmann (1979) ha conservat l'ús feminista radical de patriarcat per a referir-se al poder masculí sobre les dones i ha intentat d'analitzar la interrelació entre aquest i l'organització del procés de treball capitalista. Eisenstein (1979) defineix el patriarcat com la jerarquia sexual que es manifesta en el paper de la dona com a mare, treballadora domèstica i consumidora dins la familia. Finalment, alguns articles de Women Take Issue (1978) han usat el concepte per a referir-se d'una forma específica a les relacions de reproducció existents dins la família.

Les diferents concepcions del patriarcat en la teoria feminista contemporània corresponen fins a un cert punt a les diferents tendencies de la política feminista. El concepte de patriarcat que trobem a Sexual Politics $i$ a altres documents feministes radicals i revolucionaris parteix de lintent d'analitzar la base autònoma de l'opressió de les dones en totes les formes de societat i fornir una justificació teòrica a l'autonomia de la política fe. minista. Les ferninistes marxistes han tractat d'analitzar no solament el «patriarcat», sinó les relacions entre el patriarcat i el mode de producció capitalista. Si ho fan així és perquè no creuen que la subordinació de les dones pugui separar-se del tot de les altres formes d'explotació i opressió que existeixen en les societats capitalistes com, per exemple, l'explotació de classe i el racisme; tanmateix, rebutgen la forma en què les organitzacions socialistes i marxistes ortodoxes han marginat les dones des dei punt de vista teòric i han considerat l'opressió femenina com un simple efecte secundari de l'explotació de classe. És clar que el socialisme no garanteix de cap manera l'alliberament de les dones, com revela l'experiència de les dones dels països socialistes. Des d'un punt de vista teòric les feministes marxistes estan engatjades en l'elaboració d'una estratègia feminista socialista que pugui relacionar les lluites de les dones amb altres lluites polítiques. En la pràctica, aquesta temptativa d'enllaçar la teoria feminista amb la marxista ha estat difícil, però encara és més important de tecordar que prové d'una postura política. El fet que hi hagi feministes que teconeguin que en la societat d'avui dia -el món en què hem de viure i lluitar per tal de canviar-lo- l'opressió de les dones és unida inex. 
tricablement a l'ordre capitalista i que, per tant, comprendre l'opressió de la dona significa necessàriament que cal entendre també el capitalisme i participar en la liuita per canviar-lo.

L'interès de les feministes marxistes per analitzar teòricament la relació entre el patriarcat i el mode de producció capitalista i la preocupació política de les feministes socialistes per explorar la relació entre el feminisme i les formes de lluita de classe no posen en qüestió de cap manera l'autonomia del moviment feminista. L'organització del moviment feminista com un moviment autònom no pot deduir-se de les argumentacions teòriques sobre la naturalesa autònoma de l'opressió de la dona. La decisió d'organitzar-se com un moviment autònom i en grups autònoms és una decisió política basada en una anàlisi política de les formes de lluita feminista i de classe que existeixen en condicions històriques concretes. Aixf, doncs, voldria emfatitzar que quan m'identifico amb el projecte feminista marxista centrat en la relació entre la subordinació de la dona $i$ altres aspectes de l'organització del mode de producció capitalista, no poso en dubte el nostre dret d'organitzar-nos políticament com un moviment autònom de dones.

En aquest article penso considexar uns quants enfocaments diferents de l'anàlisi del patriarcat. Cap publicació existent ens ofereix una forma satisfactòria de conceptualitzar el patriarcat. Això planteja les qüestions de si la recerca d'una teoria del patriarcat és una empresa etrònia i de si caldria abandonar el concepte. En valorat això, convé posar en relleu que les feministes han usat precisament aquest concepte en un intent d'obrir-se camí a través de problemes polítics i teòrics reals. Per tant, si abandonem el concepte, és essencial de trobar alguna altra forma més satisfactòria de conceptualitzar la dominació masculina i la subordinació femenina i, per al feminisme marxista, de relacionar tot això amb l'organització de la totalitat del mode de producció. Fins que no elaborem aquesta anàlisi alternativa, continua oberta la quiestió de la utilitat del concepte del patriarcat per a la política i la teoria feministes. Com que l'elabotació d'una anàlisi feminista marxista adequada a la relació entre la subordinació femerina i l'organització del mode de producció capitalista és tan difícil, he decidit de consagrar aquest article a identificar una sèrie de problemes i plantejar qüestions partint d'algunes de les publicacions que usen el concepte de patriatcat En l'última part de l'article penso fer alguns suggetiments sobre un intent d'exploració d'altres formes possibles de refiexionar sobre el problema. 


\section{Feminisme radical $i$ revolucionari}

El feminisme radical ha estat extremament important en fer una anàlisi de l'optessió de la dona que ha estat influent entre els altres corrents de la teoria feminista (per exempie, el feminisme revolucionari i el feminisme marxista). En aquest apartat parlaré d'alguns aspectes de l'anàlisi que Kate Millett fa del patriarcat en el seu libre Sexual Politics (1969) i de la forma més recent d'anàlisi que ha estat desenvolupada a partir de la teoria feminista radical: el feminisme revolucionari. És clar que aquests no són els únics exponents de l'anàlisi feminista radical i revolucionària. He pres el determini de concentrar-me en aquestes interpretacions per tal com és possible de plantejar una sèrie de problemes crucials per a la teoria feminista radical i revolucionària fent referència a aqueixes obres. També parlaré breument de l'anàlisi de Christine Delphy que trobem a The Main Enemy (1977), la qual ha tingut una certa influència entre les escriptores feministes contemporànies.

Sexual Politics de Kate Millett representa una de les primetes temp. tatives serioses d'enfrontar-se amb la natura específica de l'opressió de la dona dins el moviment feminista contemporani. Per a Millett el patriarcat fa referència a una societat que és organitzada segons dos conjunts de principis: 1) que els homes dominen les dones; 2) que els homes vells dominen els joves. Aquests principis regeixen totes les societats patriarcals, segons Kate Millett, encara que el patriarcat pugui adoptar una gran varietat de formes en les diferents societats. Millett se centra en el primer d'aquests principis, la dominació de les dones pels homes, i afirma que aquesta relació entre els sexes exemplifica el que el sociòleg Max Weber anomena la Herrscbatt, això és, una relació de dominació i subordinació. També analitza els aspectes polítics de la telació entre els sexes, usant la noció de "polític» en un sentit ampli, tal com s'ha estat usant dins el moviment d'alliberació de la dona, per a referit-se a les relacions de poder entre els homes $\mathrm{i}$ les dones. Les dones es conceptualitzen com a un grup minoritari dins la societat dominant $i$ les diferències entre les dones es consideren insignificants si les comparem a les divisions existents entre dones i homes: es tracta de meres diferències d'《estil de classe». La unitat més fonamental del patriarcat és per a Millett la família, que ella considera com una unitat patriarcal dins un tot pattiarcal; les seves funcions són la socialització dels nens en rols, temperaments i status sexuaiment diferenciats i el manteniment de les dones en un estat de subordinació.

Per què, en opinió de Kate Millett, existeixen les relacions patriarcals i persisteixen al llarg de la històtia en totes les societats? Quins són els seus fonaments? Millett rebutja el punt de vista que les diferències biolò- 
giques entre els sexes puguin explicar temperaments, rols sexuals i status socials diferenciats pel que fa al gènere. (Aquesta concepció és coneguda com a reduccionisme o determinisme biològics.) ${ }^{2}$ Si bé Kate Millett rebutja aquesta explicació, no té altra teoria sobre els fonaments del patriarcat que una concepció força generalitzada de les telacions de poder. Afirma que hi ha una divisió bàsica entre homes $\mathrm{i}$ dones que implica relacions de dominació i subordinació sense explicar què és allò que en l'organització de totes les societats humanes compotta la institucionalització d'aquestes relacions de poder $i$ les difetents formes que adopten en les diferents societats la dominació masculina i la subordinació femenina. Hem de concloure que Sexual Politics ens dóna abans que tot una descripció de les relacions patriarcals i d'algunes de les seves manifestacions (per exemple, en la producció literària), però que és incapaç de fornir-nos una explicació satisfactòria dels seus fonaments.

Així, doncs, el feminisme radical introduí el concepte de patriarcat en el discurs feminista contemporani, però la seva anàlisi deixa sense explicar les formes específiques de dominació masculina i subordinació femenina. El feminisme radical tampor no explica la relació entre les relacions socials patriarcals i les relacions socials de producció, és a dir, entre les classes sexuals i les classes sociais. Des del punt de vista polític el feminisme radical s'ha centrat principalment en les liuites contra el poder masculf $i$ les institucions socials mitjançant les quals es reprodueix (matrimoni, heterosexualitat, la família). El feminisme radical també s'ha esforçat a lluitar pel que fa al paper de la dona en la reproducció biològica, una preocupació que ha estat represa més a fons pel feminisme revolucionari. Quan les feministes radicals formulen reivindicacions coherents, ho fan contra els homes com a opressors sexuals. Tanmateix, no deixen gens clar què és el que fa que els homes esdevinguin opressors sexuals, ni tampoc, cosa molt més important, quines característiques de les formes particulars de societat situen els homes en posicions de poder per damunt de les dones. Aquesta

2. Reduccionisme biològic: els conservadors politics $i$ els antifeministes han emprat sovint aquest argument pet a suggerir que, com gue les dones poden donar a llum i alletar els seus fills, estan dotades biologicament de característiques emocionals i psicològiques associades amb la maternitat com el lliurament $i$ el sacrifici $i$ que, com que el mascie sol ésser l'agressor en l'acte sexual, les dones són per tant passives tant emocionaiment com psicologica. Sovint aquests arguments es veuen reforçats pel suggetiment que jes hormones representen un paper clax en la causació d'aquestes diferències psicològiques. Tals explicacions negligeixen la important distinció entre sexe biològic i gènere, que és construït socialment. Així mateix, tampoc no expliquen perquè les diferències sexuals i generiques adopten formes diverses en les formes diferents d'organització social. 
és una de les qüestions que hauria de plantejar una teoria adequada del patriarcat.

El feminisme revolucionari ha desenvolupat recentment l'anàlisi feminista radical de la subordinació femenina i assegura que les diferències de gènere poden explicar-se en termes de les diferències biològiques entre homes $\mathrm{i}$ dones. El feminisme tevolucionari de fet elabora una teoria del patriarcat i de la classe sexual arrelada en les capacitats reproductives de les dones. Segueix l'anàlisi de The Dialectic of Sex (Firestone, 1971), en què Shulamith Firestone tracta de resoldre el dilema plantejat per Sexual Politics declarant que la base de l'opressió de la dona radica en les seves capacitats reproductives en la mesura en què aquestes han estat controlades pels homes. Com a exemple de la tendència feminista revolucionària m'estendré sobre alguns dels articles reproduïts a Scarlet Women (número cinc).

Sheila Jeffreys ens diu a "La necessitat d'un feminisme tevolucionari» (Scarlet Women 5:10) que existeixen dos sistemes de classes socials: 1) el sistema de classe econòmic, que es basa en les telacions de producció; 2) el sistema de classe sexual, que es basa en les relacions de reproducció. Segons Sheila Jeffreys, és el segon sistema de classe, el sistema de classe sexual, el que explica la subordinació de les dones. El concepte de patriarcat es refereix a aquest segon sistema de classe, a la dominació de les dones per part dels homes que es basa en la propietat i el control per part dels homes dels poders reproductius de les dones.

Finella McKenzie en el seu article «Feminisme i socialisme» (Scarlet Women 5) esbossa les formes en què la diferenciació reproductiva dóna lloc al poder i control masculins. McKenzie afrma que la primera divisió del treball fou entre homes i dones i que si fou així va ésser a causa de les capacitats reproductives de les dones i a la força més gran dels homes. Com que les dones al llarg de la història han estat supeditades a la seva biologia, segueix McKenzie, això les ha fet ésser dependents dels homes per a la seva supervivència física, especialment durant la menstruació, el part, etc. Aquesta dependència femenina establi un sistema desigual de telacions de poder dins la família biològica: un sistema de classe sexual. Finelia McKen. zie identifica així tres aspectes de la subordinació de les dones: les seves diferents capacitats reproductives, la seva manca de control sobre aquestes i la conversió per part dels homes de la dependència causada per la biologia de les dones en una dependència psicològica. Així, com assenyalen Jaina Hanmer, Kathy Lunn, Sheila Jeffreys i Sandra MacNeill a «Classe sexual: Per què és important anomenar les dones una classe?», no és la biologia femenina la que és opressiva, sinó el valor que els homes li donen i el poder que aconsegueixen a causa del seu control sobre ellâ. En opinió de 
Sheila Jeffreys, les formes precises de control canvien en funció del període històric i cultural i de les mutacions del sistema de classe econòmic. Nogensmenys, el que constitueix la base inalterable del pattiarcat és la constància del poder $\mathrm{i}$ el control dels homes sobre les capacitats reproductives de les dones, segons les feministes revolucionàries. Des del punt de vista estratègic el feminisme revolucionari està engatjat a desenvolupar la consciència de classe de les dones, és a dir, la consciència per part de les dones del funcionament del sistema de classe sexual. Els articles de Scarlet Women 5 destaquen la importància de les activitats de presa de consciència i de desemmascarament del poder mascle $\mathrm{i}$ el seu mode de funcionament rnitjançant actes centrats sobre la violació, la violència sexual i la violència dins la família.

L'andilisi feminista revolucionària, que cerca les arrels del patriarcat i la subordinació femenina en les diferències reproductives entre els sexes, planteja molts problemes. En primer lloc, és teduccionista biològica i per tant és incapaç d'explicar les formes que les diferències sexuals adopten dins eis diferents modes d'organització social, que considera com a donats. En segon lloc, deftzeix el concepte de reproducció d'una forma extremament estreta i el limita a l'acte físic de la reproducció dels fills. Les diferències reproductives entre homes $i$ dones no queden situades dins de cap sistema de relacions socials i hom no dóna cap explicació de les caracterís. tiques de les formes particulars de societat que originen l'agressivitat i dominació masculina d'una part i la passivitat i dependència femenina de I'altra. Segons aquesta anàlisi, la causa de l'opressió femenina rau en l'ànsia intemporal de poder dels bomes sobre les dones. En tercer lloc, el feminisme revolucionari parteix de l'existència de dos sistemes autònorns de classes socials, les classes economiques i les classes sexuals, i no ens diu gaire sobre les relacions entre aquests. L'anàlisi de la producció sobre la qual es basen les classes socials resta així inalterada tant pel treball teòric feminista com per les Huites de les dones que tenen per objecte la reproducció. Això té greus implicacions polítiques. No queda gens clar quina seria la concepció feminista revolucionàtia d'una societat no patriatcal i com es reproduiria aquesta societat. Tampoc no queda clar quina estratègia tevolucionària hauria d'adoptar el feminisme revolucionari per tal d'assolir aquesta societat. Finalment, si hom parteix del fet que els homes tenen un desig biològic innat de subordinar les dones, tcom setia possible que les dones s'alliberessin prou del poder i del control dels homes per tal de lluitar en pro d'una forma no patriarcal de societat?

En els seus assaigs publicats sota el títol The Main Enemy, Christine Delphy elabora una forma aiternativa d'anàlisi del patriatcat que anomena materialisme feminista. Com que les argumentacions de Christine 
Delphy han estat repassades sistemàticament en l'obra de Michèle Barrett i Mary McIntosh (1979), només en parlaré en aquest article en la mesura en què són pertinents als problemes teòrics que suposa l'anàlisi del concepte del patriatcat $i$ de les relacions socials patriarcals. Les principals tesis de Christine Delphy són les següents: En la societat capitalista hi ha dos modes de producció: 1. El mode de producció industrial, que constitueix el centre de l'explotació capitalista. 2. El mode de producció familiar, en el qual la dona presta serveis familiars, en el qual té lloc la criança dels nens $i$ en el qual es produeixen també alguns béns per a ús $\mathrm{i}$ canvi, bé que això passi cada vegada menys a mesura que es produeixen més i més mercaderies dins el procés de treball capitalista. Així, segons aquesta concepció, l'explotació i l'opressió de la dona dins la família és conseqüència del control de l'home sobre les activitats productives i reproductives que tenen lloc dins el mode de producció familiar. Però en afirmar que la familia té prioritat damunt totes les altres relacions socials (ja que en virtut del matrimoni les dones comparteixen una posició de classe comuna), Christine Delphy artiba a una postura teòrica en què el patriarcat i el capitalisme esdevenen esferes autònomes, cadascuna amb el seu propi sistema d'explo. tació i classes socials. La conseqüència d'aquest enfocament és que no aprecia les complexitats i les contradiccions dels lligams entre el procés de producció i la família i la forma en què en última instància les relacions socials de producció transformen totes les telacions socials, incloses les relacions familiars, en el curs del desenvolupament del capitalisme. Això té implicacions tant per a la seva anàlisi del treball assalariat com per a la seva visió de la família, atès que no parla de les condicions que prevalen a la indústria en gran escala, les formes de treball que exigeix el capital en determinades condicions històriques $i$ les formes en què les dones s'han vist atretes cap a la producció social fora de la família en resposta a algunes d'aquestes exigències. Si bé assenyala correctament la doble càrrega que les dones han de suportar quan entren en la producció social com a treballadores assalariades, negligeix l'observació important que Barbara Taylor féu a «EI nostre treball i el nostre poder» (1975-1976) que el treball femení adopta diferents formes en el procés de treball capitalista i en la família. Les dones són explotades en ambdues condicions, però de formes diferents $\mathrm{i}$ amb diferents avantatges tant per al capital com per a llurs marits. Presumir, com fa Christine Delphy, que el patriarcat resideix només en la família suposa fer una descripció unilateral que és incapaç d'explicar per què, en última instància, les dones sofreixen explotació tant dins el procés de treball com dins la família. 


\section{Feminisme marxista}

A diferència de l'obra de les feministes radicals i tevolucionàries, les anàlisis feministes marxistes del patriarcat s'encaminen cap a la temptativa de comprendre la relació entre el patriarcat i els altres aspectes de l'orgatització del mode de producció. Aixú, el mateix problema que trobem als assaigs de Christine Delphy The Main Enemy, o sia el problema de relligar la família amb la producció, apareix també en el feminisme marxista. Les ferninistes marxistes han definit el patriarcat de diverses maneres $i$ han explicat de diferents formes la relació entre el patriarcat i el mode de producció capitalista. Així mateix, dins la teoria marxista en general trobem una gran varietat d'enfocaments quant a la definició dels modes de producció. Per consegüent, les marxistes feministes prenen part en molts dels debats que tenen lloc en el si del marxisme així com en les controvèrsies teòriques feministes.

En aquest apartat vaig a pariar de dues menes d'anàlisi feminista marxista del patriarcat. La primera defineix el patriarcat en termes ideològics i basa l'anàlisi de la ideologia en conceptes derivats de la teoria psicoanalítica. La segona defineix el patriarcat en termes de les relacions de reproducció o del sistema de gènere sexual. Tots dos enfocaments intenten d'escatir la relació entre el patriarcat i el mode de producció capitalista. En aquest apartat he seleccionat una sèrie de textos $i$ articles que al meu parer plan. tegen qüestions centrals per a l'anàlisi del patriatcat, però la meva revisió no pretén d'ésser exhaustiva. La meva intenció és de tractar d'examinar diversos enfocaments diferents de la qüestió i considerar alguns dels problemes que plantegen més que no pas de subministrar una relació completa de la literatura feminista marxista. Espero que alguns autors no en sofreixin injustament.

\section{El patriarcat com a ideologia: Juliet Mitchell, psicoanalisi $i$ feminisme}

Una de les partidàries més decidides de la concepció que el patriarcat pot definir-se com una ideologia és Juliet Mitchell, que exposa les seves

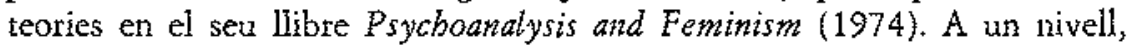
la psicoanàlisi constitueix una teoria del complex procés pel qual el nen amb una disposició bisexual és iniciat a la cultura humana, adquirint així les formes específques de feminitat i masculinitat que són apropiades al seu lloc dins la cultura. ${ }^{3}$ Una de les aportacions de J'obra de Juliet Mitchell

3. No voldria menystenir la importància dels escrits de Juliet Mitchell sobre el 
ha estat Ia de fornir-nos una explicació teòrica del desenvolupament de la feminitat i de la constitució de la condició femenina basada en conceptes psicoanalítics $i$ que ha estat de gran impottància en la formació de les teories psicoanalítiques de Ia feminitat. En Psycboanalysis and Feminism podem discernir també un segon nivell d'anàlisi que ha estat influent entre les autores feministes sobre la ideologia del patriarcat. Es tracta d'un intent d'interpretació dels orígens i fonaments del patriarcat dins la cultura humana.

Juliet Mitchell likga les dues parts de la seva anàlisi amb l'asseveració que per a Freud el concepte psicoanalític de l'inconscient és un concepte de la transmissió $i$ herència de les lleis culturals de la humanitat. Mitchell ens diu que, en comprendte com opera l'inconscient, és possible d'assolir un cert coneixement sobre el funcionament de la cultura patriarcal. La característica definitótia d'una cultura patriarcal és, per a ella, que dins d'aqueixa cultura el pare assumeix simbòlicament el poder sobre la dona, i ens assegura que són els pares i els seus «representants» i no els bomes (com diuen les feministes radicals i revolucionàries) els que tenen el poder determinat sobre les dones en la cultura patriatcal. Juliet Mitchell es dreça contra les formes biològiques d'explicació de les causes per les quals el pare ostenta aquest poder (és a dir, ataca les formes d'anàlisi reduccionistes biològiques) i afirma que el pare assumeix aquest poder simbòlicament als inicis de la cultura humana. Per què? Per a contestar aquesta pregunta fa servir l'anàlisi de Lévi-Strauss dels sistemes de parentiu (1969). Segons Lévi-Strauss, les societats humanes estan basades en relacions d'intercanvi, $i$ una de les formes fonamentals d'intercanvi és el de dones per homes. Aquesta forma d'intetcanvi explica la posició social que les dones ocupen en totes les societats bumanes. A la base d'aquesta anàlisi de les raons per les quals es fan servir com objectes de canvi les dones i no els homes hi ha la interpretació freudiana de la universalitat del tabú de l'incest (Freud: 1950). Aquesta regla negativa dóna origen a la regla de l'exogàmia, que dicta quines persones s'han de casar fora de la seva pròpia família nuclear. Segons Lévi-Strauss, és aquesta necessitat la que determina l'ús de les dones com objectes de canvi.

Emparant-se amb Lévi-Strauss, Juliet Mitchell argumenta que la universalitat del patriarcat està arrelada en l'intercanvi de les dones pels homes, la necessitat del qual es basa a la vegada en la universalitat del

desenvolupament de la masculinitat i la feminitat i la influència que tenen sobre altres publicacions feministes. Ací, però, no m'interessen aquestes qüestions, sinó eis arguments de Mitchell sobre el patriarcat i la ideologia que formula d'una forma un xic esquemàtica en la conclusió de Psychoanalysis and Feminism. 
tabú de l'incest. D'aquesta forma hom postula el patriarcat com una estructura universal en totes les societats humanes. Tanmateix, la nostra autora sosté que cada mode de producció determinat expressa aquesta llei universal del patriarcat de diferents formes ideològiques. En aquest punt intenta de lligar la seva anàlisi amb la teoria marxista dels modes de producció. Segons ella, a la societat capitalista s'han desenvolupat les condicions per a la desaparició del tabú de I'incest $i$ les estructures de parentiu, però tanmateix aquestes estructures han romàs. Per a Juliet Mitchell, el capitalisme ha fet que la liei patriarcal esdevingués redundant; hi ha una contradicció entre l'organització de l'economia capitalista i la continuació de l'existència del patriarcat. Al centre d'aquesta contradicció hi trobem les dones en el seu paper reproductiu. Les dones contintten essent defunides per les estructures de parentiu, mentre que els homes entren en les estructures de dominació de classe de la història. Juliet Mitchell apunta que cal que la Iluita feminista sigui dirigida contra e! mode de patriarcat ideològic que ha esdevingut cada cop més redundant. Així, la lluita feminista és conceptualitzada com una forma de tevolució cuitural l'objecte de la qual és de trans. formar els fonaments de la cultura patriarcal.

L'anàlisi de Juliet Mitchell del patriatcat sembla problemàtic en diversos aspectes. Ens referim sobretot a la seva utilització de la teoria social de la ideologia d'Althusser $(1969,1970,1971)$ com a marc sociològic bàsic. Atès que el marc que empra per analitzar el patriarcat ha tingut una certa influència entre algunes autores feministes, voldria fer uns comentaris sobre les implicacions que comporta el seu ús. Aquest marc no ens ofereix cap teoria satisfactòria dels fonaments del patriarcat, ja que es basa en la teoria vagament formulada que Freud elabora a Tòtem $i$ tabú i en la tesi de Lévi-Strauss que les relacions d'intercanvi constitueixen els fonaments de la cultura humana i de la subordinació de les dones. El problema és que Lévi-Strauss no ens dóna cap explicació del perquè són els homes que canvien dones $\mathrm{i}$ per consegüent dels fonaments de la dominació masculina sobre les dones. ${ }^{4}$

Una altra sèrie de problemes es refereixen a la concepció de Juliet Mitchell de la ideologia, concepció que deriva d'una interpretació althusseriana de la societat. En els seus primers escrits For Marx (1969) i Reading Capital (1970), per exemple, Louis Althusser elabora una concepció de la societat que es resol en una sèrie de nivelis o pràctiques analíticament dis-

4. A més, les proves cmpítiques ens donen a entendre que en les societats matrilineals són els oncles materns i no els pares els que «bescanvien» les dones. Això posa en dubte l'afirmació de Juliet Mitchell que la subordinació de les dones i les telacions socials patriarcals radiquen precisament en el poder del pare de bescanviar les dones. 
tints: l'econòmic, el polític, l'ideològic. Althusser presumeix que l'economia determina els altres nivells «en última instància» i que el nivell ideològic té una «autonomia relativa» de la seva base econòmica. En els seus assaigs Lenin and Pbilosophy (1971), i especialment en l'article titulat \&La ideologia i els aparells ideològics de I'Estat», Louis Althusser elabora aquesta noció d’ideologia aprofundint-la en dos sentits. Primer, analitza les relacions funcionals entre les institucions ideològiques específiques (que anomena els aparells ideològics de l'Estat), la reproducció de la força de treball i les relacions socials de producció en el mode de producció capitalista. D'aquesta forma, connecta el nivell ideològic del mode de producció al nivell econòmic i manté que les estructures ideològiques --per exemple, les escoles- són necessàries per al capitalisme. Però aquesta mena de teoria -el funcionalisme- no explica per què les institucions i pràctiques ideològiques prenen una forma específica ni tampoc pren en consideració la lluita de classes. Les «necessitats» del capital determinen tot el que passa.

En segon lloc, elabora una concepció general de la ideologia. En aquesta interpretació suggereix que la "constitució de la subjectivitat», és a dit, la forma en què el subjecte es concep a si mateix $i$ el seu lloc en el món constitueix el tret central de la ideologia, que no és sinó un conjunt de «relacions viscudes». Juliet Mitchell basa els seus propis arguments en aquest enfocament teòric i en la concepció del psicoanalista francès Jacques Lacan, envers el qual Louis Althusser està endeutat per la seva forma de considerar la relació del que concebem correntment com a l'individu i el món. Tots tres creven que la teoria de Freud pot oferir una interpretació materialista de la constitució de la subjectivitat.

En el cos principal del seu text Juliet Mitchell defineix el patriarcat com la llei simbòlica del pare que, segons Freud i Lévi-Strauss, constitueix una llei universal que existeix a totes les societats. Però no queda gens clar què significa l'ordre simbòlic i quina és la selació entre aquest i l'anàlisi de la ideologia. Aquest problema es presenta d'una forma particularment greu en l'apartat frnal de Psycboanalysis and Feminism en què Mitchell passa de l'anàlisi de l'ordre simabòlic a l'anàlisi de la ideologia, tedefinint l'ordre simbòlic com a ideologia en tractar de connectar la teoria freudiana amb la marxista. La interpretació de Mitchell del patriarcat es basa en la teoria de Freud que tracta d'explicar com és que els subjectes individuals esdevenen «masculins» $i$ «fermenins». Aquesta teoria és essencialment universalista i s'aplica a totes les formes de cultura humana. Resulta doncs dífícil d'integrar satisfactòriament aquesta concepció amb una anàlisi marxista. En l'anàlisi de Mitchell copsem una tensió entre una teoria universalista del patriarcat basada en la subordinació de les dones a la llei del pare i una interpretació marxista que pretén d'oferir una teoria històrica- 
ment específica dels modes de producció $\mathrm{i}$ de les formes d'Estat $\mathrm{i}$ ideolo gia que apareixen dins els modes de producció específics. Mitchell sosté que els orígens del patriarcat tenen les seves arrels en el tabú de l'incest i en l'intercanvi de dones pels homes a què dóna loc aquest. Ignora el desenvolupament històric del patriarcat $\mathrm{i}$ les formes concretes que adopta.

En el curs de la seva obra l'anàlisi de Mitchell de la ideologia passa de ser una teoria de l'autonomia relativa de la ideologia a una teoria de l'autonomia absoluta de la ideologia. A més, com que creu que la subordinació de les dones dins les relacions socials patriarcals és ineludible, ja que els orígens de la seva subordinació són identificats amb els orígens de la cultura humana, no queda gens clar què pot fer la lluita feminista per a canviar el destí de la dona.

Alguns dels crítics d'Aithusser i Mitchell, per exemple Hirst (1976) i certs articulistes de la revista $m / f$ números 1 i 2 (1978), han reconegut que és contradictori adoptar ensems una concepció universalista de la constitució del subjecte genètic derivada de les anàlisis de Freud i Lévi-Stzauss $i$ una concepció materialista històrica dels modes de producció. Aquests crítics han intentat de resoldre la contradicció a base de professar obertament allò que Juliet Mitchell només arriba a implicar. La tevista $m / f$ ha desenvolupat una forma de teoria del discurs per tal d'explotar aquest problema. La seva interpretació sosté que cal analitzar la construcció social de la dona en relació als discursos dins els quals es constitueix, amb la implicació que totes les formes de pràctica es conceptualizzen com a discursos i que no hi ha una sola mena de discurs que tingui primacia sobre els altres. Encara que aquest no fóra sinó un mecanisme per a resoldre una construccí́ teòrica important que sotja Psycboanalysis and Feminism, Ia seva relació $\mathrm{amb}$ el materialisme històric virtualment desapareix. $\mathrm{Si}$ analitzem totes les formes de discurs independentment les unes de les altres, la primacia de les relacions socials de producció, que ha estat un dels trets característics de l'anàlisi marxista, s'esvaeix del matc teòric.

La concepció de Juliet Mitchell de la societat com a un conjunt de pràctiques distintes té implicacions tant per a la seva concepció del mode de producció capitalista com per a la seva anàlisi de la ideologia. Car, igual que Christine Delphy $\mathrm{i}$ algunes de les autores feministes marxistes que tractaré al proper apartat, distingeix entre uel mode de producció [i] el mode de reproducció ideològic» (Mitchell, 1974: 412). Encara que ens diu molt poc del mode de producció econòmic, és clar que la seva interpretació es basa en una definició econòmica del mode de producció, una definició formulada en termes d'una concepció estreta del procés de treball en comptes de ser-ho sobre les relacions socials de producció i l'organització del mode de producció capitalista en la seva totalitat. Les relacions de 
reproducció, que es defineixen com a relacions ideològiques, s'analitzen com a estructures independents que estan integrades funcionalment dins el mode de producció (econòmic). És veritat que Mitchell es refereix a una contradicció entre el mode de patriarcat ideològic i el mode de producció capitalista quan sosté que les condicions de l'existència del patriarcat han deixat d'existir, però aquesta contradicció és analitzada en termes més formals que històrics i no és de cap manera central a la seva anàlisi. En el proper apartat de l'article tornaré a estudiar alguns dels problemes que planteja l'anàlisi de la reproducció, ja que algunes de les qüestions que es presenten a Psycboanalysis and Feminism poden identificar-se més clarament en algunes de les publicacions feministes marxistes més recents.

\section{El patriarcat i les relacions socials de reproducció}

Algunes de les publicacions més recents de la literatura feminista marxista s'han centrat en les relacions socials de reproducció $i$ han tractat del pes relatiu que caldria concedir a la producció i a la reproducció en la teoria feminista marxista. Crec que l'interès en estudiar l'opressió de les dones en termes del concepte de reproducció i en situar el patriarcat dins les relacions socials de reproducció deriva d'una sèrie de factors:

1. Noves línies d'investigació dins l'anàlisi feminista radical, que han produït nombroses descobertes sobre aspectes específics de l'opressió de la dona relatius a la reproducció (part, avortament, maternitat, per exemple).

2. Reconeixement que hi ha aspectes de l'opressió de la dona que desborden el marc de mode de producció capitalista. En algunes obres antropològiques feministes aquest punt pren la forma de l'afirmació de la universalitat dels papers domèstics, maternals i reproductius de la dona.

3. La creença que les relacions socials patriarcals no poden derivarse directament del capital i el desig consegüent de donat cos, de complementat i de desenvolupar la visió marxista del procés de producció amb una visió del procés de reproducció.

4. Un retorn a l'afirmació que fa Engels en el «Prefaci» a la primera edició de L'origen de la família, la propietat privada i l'Estat que:

«El factor determinant en la històtia és, en última instància, la producció i la reproducció de la vida immediata $[. .$.$] que té un caràcter doble.$ D'una banda, la producció dels mitjans de subsistència $[\ldots]$ de l'altra, la producció dels mateixos éssers humans. Les institucions socials sota les 
quals viuen els homes d'un país determinat estan condicionades per dos tipus de producció; per l'estadi de desenvolupament del treball d'una part, i de la família de l'altra.» (Engels, 1968: 455.)

Aquests paràgrafs tan citats del prefaci d'Engels han ofert una justificació clàssica dintre el marxisme per analitzar l'esfera de la reproducció en tant que un aspecte de l'analisi del mode de producció capitalista.

5. La publicació a França del llibre de Claude Meillassoux Femmes, Greniers et Capitaux (1975) la preocupació central del qual és la qüestió d'esbrinar per què les relacions socials basades en la familia (o la comunitat domèstica) continuen tenint una importància tan gran per al sistema capitalista. Uns quants articles elaborats recentment sobte la teoria de la reproducció tenen per objecte iniciar un debat crític amb les tesis de Meillassoux: vegeu O'Loughlin (1977), Mackintosh (1977) i Edholm i altres (1977).

Com Edholm $i$ altres assenyalen a «Com cal conceptualitzar les dones», el concepte de reproducció s'ha emprat d'una forma extremament imprecisa dins la literatura ferninista marxista. Però crec que molts dels escrits que usen el concepte de reproducció comparteixen, a un nivell general, una sètie de característiques, que voldria tractar breument aquí.

Un bon nombre d'autors, com ara McDonough i Harrison (1978), diversos signants dels articles apareguts a Women Take Issue (1978), Hartmann (1979a i 1979b) i Eisenstein als seus articles de Capitalist Patriarchy and the Case for Socialist Feminism (1979) comparteixen el supòsit que l'especificitat del patriarcat radica en les relacions de reproducció, que a la vegada estan localitzades dins la família. Nogensmenys, uns quants autors defineixen les relacions socials de reptoducció com a relacions materials derivades, per exemple, del control del treball de la dona i altres com a relacions ideològiques o culturals. Així, per a posar l'exemple d'un article que defineix les relacions de teproducció en termes materialistes, McDonough i Harrison sostenen que el patriarcat es basa en el control del treball de la dona en la família i en la fidelitat sexual i la procreació de la dona. En un passatge que s'assembla molt a una formulació de Delphy a The Main Enemy, McDonough i Harrison diuen que les formes específques de control sobre la reproducció que caracteritzen el patriarcat apareixen amb el matrimoni, en què la dona dóna a canvi la seva força de treball i la seva capacitat de procrear durant un determinat període: tota la vida. Encara que les formes del patriarcat variïn segons la classe -afirmen-, atès que el control de la sexualitat i la fecunditat de la dona en la famúlia 
burgesa es refereix a la producció dels hereus, mentre que en la família proletària es refereix a la reproducció de la força de treball, la forma bàsica de les relacions patriarcals continua essent la mateixa. McDonough i Harrison mantenen que el desenvolupament uiterior del concepte de patriarcat ha de girar entorn de la interrelació entre les relacions de producció $\mathrm{i}$ les relacions de reproducció. De tota manera, la seva argumentació tendeix a perpetuar una mena d'escissió analítica que separa l'esfera de la reproducció de l'esfera de la producció, com illustra el passatge següent:

«Bé que con a marxistes creiem que és essencial de donar prioritat analítica a l'esfera de la producció, com a ferninistes creiem que és igualment important de concedir una gran atenció al concepte de reproducció humana per tal de comprendre la naturalesa especifica de l'opressió de la dona.» (1978: 28.)

Alguns articles, per exemple el de Lucy Brand et al. «Les dones "dins i fora" les relacions socials de producción (1978) consideren la telació entre el paper de la dona en les dues esferes, però això ho fan solament les conseqüències que té per al treball assalariat de la dona el seu paper reproductor. Així, doncs, la família és considerada el lloc privilegiat de la subordinació femenina i el mode de reproducció és tingut per funcionalment necessati per al capital, pel seu desig de força de treball barata i flexible.

Zillah Eisenstein, per la seva banda, creu que la qüestió es resol en com s'ha de «formular el problema de la dona com a mate i treballadora, reproductora i productora» (1979: 1). Les relacions cabdals que determinen l'opressió de la dona són la superioritat masculina i el capitalisme:

«La $[\ldots]$ dinàmica de poder $[\ldots]$ deriva de les telacions de pro ducció de classe i de les relacions socials de jerarquia sexual» (1979: 1).

Eisenstein concep la societat integrada per dues esferes: d'una banda, el procés de treball capitalista, en què es dóna l'explotació, i de l'altra, la jerarquia sexual patriarcal, en què la dona és mare, treballadora domèstica i consumidora i en què es dóna l'opressió de la dona. En la seva concepció, el patriarcat no és analitzat com un resultat natural de la diferenciació biològica, com en l'obra de Shulamith Firestone Tbe Dialectic of Sex (1971), ni com una conseqüència de l'existència universal del complex d'Edip, com en Psychoanalysis and Feminism, sinó que és conceptualitzat com un resultat de les interpretacions ideològiques i polítiques de la diferenciació biològica. Això és el que vol dir quan empra les expressions de relacions 
socials de reproducció o de sistema genèric sexual..$^{5}$ Per a Zillah Eisenstein aquestes relacions de teproducció no són específicament telacions capitalistes, sinó relacions culturals que són arrossegades d'un període a un altre. Sí bé l'organització econòmica de la societat canvia, el patriarcat, que se situa en les relacions socials de reproducció, constitueix un sistema d'ordenació $i$ control jeràrquics que ha estat usat en diverses formes d'organització social, entre elles el capitalisme.

En els dos exemples de teories de la reproducció social que he examinat, en el primer cas aquestes es defineixen en termes del control sobre el treball de la dona, la seva fecunditat $i$ la seva capacitat de procreació, és a dir, en termes materialistes, $i$ en el segon cas com a telacions ideològiques que participen directament en la transformació del sexe en gènete. En ambdós casos hom dóna prioritat a les relacions de reproducció a I'hora de definir l'opressió de la dona. Aquestes relacions poden tenir conseqüències per a l'organització de la producció, o poden estar relacionades amb ella des del punt de vista funcional, però l'especificitat de l'opressió de la dona és percebuda principalment en termes de les relacions de reproducció. En el proper apartat intentaré d'assenyalar alguns dels problemes que planteja aquesta mena d'anàlisi.

\section{Una nota sobre la producció, la reproducció $i$ el patriarcat}

Un dels temes que he tractat de subratllar en examinar una selecció de les publicacions sobre el patriarcat és que en moltes hi predomina una forma d'anàlisi que conceptualitza la societat en dues estructures separades. Segons els autors, aquestes estructures són denominades de formes diverses: sistema de classe econòmic/sistema de classe sexual (el feminisme revolucionari i Firestone); mode de producció familiar/mode de pro ducció industrial (Delphy); capitalisme/patriarcat (Hartmann, 1979a); relacions socials de producció/relacions socials de reproducció (McDonough i Harrison, Women Take Issue). Així mateix els diferents autors conceptualitzen aquestes estructures separades com a clars deterninants del canvi històric que interaccionen entre si, s'acomoden l'una amb l'altra o entren en conflicte mutu (Hartmann, Einstein) o bé que estan relacionades funcionalment entre si. (Bland et al.)

Voldria, a guisa de conclusió, escatir alguns dels problemes que es presenten si el patriarcat i el capitalisme, o les relacions socials de repro-

5. El terme «sistema genèric sexual» fou usat per Rubin (1975) i és adoptat en alguns dels altres assaigs recollits a Eisenstein (ed.) (1969) com un mitjż alternatiu de conceptualització de les relacions de producció. 
ducció i les relacions socials de producció, es tracten com a estructures independents.

Primer, com han assenyalat Felicity Edholm, Olivia Harris i Kate Young a "Com cal conceptualitzar les dones», hom ha emprat el concepte de teproducció de maneres molt diferents. Aquestes autores proposen distingir tres formes de reproducció: 1 . La reproducció social, és a dir, la reproducció de les condicions de producció totals; 2. La reproducció de la força de treball; 3 . La reproducció biològica. Entre els marxistes els debats sobre la primera d'aquestes formes de reproducció, la teproducció social, han estat força associats amb els debats sobre el concepte de mode de producció, mentre que l'anàlisi de la reproducció de la força de treball ha estat una de les preocupacions centrals de les feministes marxistes imbricades en el «debat sobre el treball domèstic». Crec que és força difícil de donar un significat rigorós dels diversos usos del terme «reproducció», d'escatir, per exemple, si cal incloure la reproducció biològica dins la categoria de la reproducció de la foxça de treball i de comprendre com cal explicar el control de la sexualitat de la dona en termes del concepte de reproducció. Penso que si ens hem interessat per l'estudi de la reproducció ha estat per tal d'evitar una versió mecanicista del marxisme que posa èmfasi només en la producció $i$ el procés del treball $i$ per tal de tractar especificament les activitats familiars de la dona, que el marxisme ha ignorat repetidament. De tota manera, com diuen Felicity Edholm, Olivia Harris i Kate Young (1977: 111), potser estem equivocats quan «advoquem pel desenvolupament de tot un conjunt de nous conceptes amb la intenció de comprendre la reproducció humana». Possiblement el nostre desig d'avançar en aquest sentit no fa més que teflectir la forma en què fetitxitzem la reproducció.

El segon problema és que la separació de la reproducció o del patriarcat d'altres aspectes del mode de producció ha fet que el pensament feminista no es dediqués a criticar ni a transformar l'anàlisi marxista de la producció. I tanmateix, des del punt de vista teòric, l'anàlisi marxista del procés de producció ha estat força insatisfactòria, ja que les anàlisis de la producció són sovint economicistes, el procés de treball ha estat divorciat de les relacions socials de producció com a un tot $i$ hom ba exclòs sovint d'aquestes anàlisis el treball assalariat femení.

Aquesta deffciència teòrica té greus implicacions polítiques. Els homes que professen el marxisme defineixen generalment la classe obrera fent referència al procés de treball (és a dir, els treballadors assalariats que no tenen en propietat els mitjans de producció $i$ subsistència) $i$ alguns d'ells ho fan d'una forma encara més restrictiva fent referència als treballadors productius que produeixen directament plus-vàlua dins el procés de treball 
capitalista. Aquesta concepció de la classe deriva d'una concepció del mode capitalista de producció que només es fixa en el procés productiu. No obstant això, és impossible de copsar la complexitat de les relacions difetencials que els homes $i$ les dones tenen envers la producció, $i$ les diferents formes que adopta la seva consciència, fent solament referència a la pro. ducció. Cal situar l'anàlisi de la producció dins la totalitat de les relacions socials de producció, atès que la posició de totes les categories del treball no pot ésser compresa satisfactòriament sense fer referència a la família i a l'Estat. Estudis recents sobre les respostes diferencials dels treballadors masculins $i$ femenins en els conflictes laborals han començat a illustrarnos un xic sobre aquest procés. En «Vaga de zel» (1978) Beatrix Campbell i Valerie Charlton comenten les diferents reivindicacions que ets homes $\mathrm{i}$ les dones treballadors feren a la fàbrica Ford. Els homes demanaven sous més alts, però les dones volien l'escurçament de les hores de treball setmanals, l'abolició de les distincions contractuals entre treballadors amb dedicació plena i parcial i la concessio de llicències. Aquestes reivindicacions només es poden entendre si conceptualitzem la posició dels treballadors dins. el procés de producció més àmpliament del que és corrent en la teoria marxista. En la meva opinió, quan les feministes marxistes trebailen sobre quiestions d'ideologia, reproducció i patriarcat, tant si volen com si no, estenen les implicacions de la crítica feminista a l'anàlisi marxista de la producció.

En tercer lloc voldria fer l'observació que és impossible una noció de la producció que no impliqui al mateix temps una noció de la reproducció. Tot mode de producció suposa la producció i la reproducció, tant des del punt de vista històric com lògic. Per tant, convé que tractem de comprendre les interrelacions entre la producció i la reproducció com a part d'un procés únic i que considerem les formes en què aquestes s'han transformat històricament. Crec que és necessari d'analitzar el desenvolupament del procés de treball, la fanólia i l'Estat, i la relació entre ells a mesura que s'ha produit l'acumulació de capital. Així com el capitalisme no va crear el procés de treball capitalista, sinó que el va desenvolupar al llarg d'un procés prolongat i desigual en el si de formes d'organització de la força de treball històricament determinades, ${ }^{6}$ tampoc no va crear la família patriar$\mathrm{cal}$, però la va desenvolupar a partir de l'economia domèstica patriatcal que ja existia. Cal que analitzem el desenvolupament històtic d'aquestes institucions, les interrelacions entre elles $i$ les formes en què s'han transformat l'estructura de la família i la nostra experiència de la vida familiar a mesura que s'ha anat desenvolupant el mode de producció capitalista.

\section{Veure Samuel (1977),}


Al principi d'aquest article he afrmat que el discurs feminista contemporani va adoptar el concepte de patriarcat en un intent de contestar importants qüestions sobre la nostra experiència de l'opressió i fornir-ne tota una anàlisi global. Al llarg d'aquest article he comentat algunes de les versions de la teoria feminista que, al meu entendre, no ho aconsegueixen. De tota manera, convé posar en relleu que el marxisme no ha tesultat ésser totalment inadequat per a la tasca de l'anàlisi de l'opressió de la dona. Com ha assenyalat Heidi Hartmann, el marxisme ha fet una anàlisi de la «qüestió de la dona», però ha tractat el tema de la "qüestió fe. minista» d'una forma insatisfactòria. ${ }^{7}$ Encara que he criticat alguns dels usos del concepte, m'agradaria de concloure subratllant algunes de les formes en què crec que podria ésser útil d'elaborar-lo i fer-ne ús. En primer lloc, crec que una teoria satisfactòria del patriarcat hautia d'ésser històricament específica i que hauria d'explotar les formes de patriarcat que existeixen dins els modes de producció concrets. Això vol dir que pot ésser que les formes de patriarcat que existeixen en la societat capitalista siguin diferents de les formes existents a les societats precapitalistes o socialistes. No crec que l'existència d'una diferenciació biològica dels sexes en els diversos modes de producció pugui invalidar aquesta argumentació, atès que la diferenciació biològica és menys significativa que les diferents formes de construcció social del gènere i les formes d'institució social en què es dóna el patriarcat en les diverses societats.

En segon lloc, cal investigar les formes de patriarcat que existeixen en les institucions socials concretes. Penso que estem equivocats en creure que la dominació adopta la mateixa forma en totes les formacions socials i en tots els tipus d'institucions socials que hi ha dins la societat. Per exemple, les formes de dominació patriarcal que existiren quan l'economia domèstica era la unitat primària de producció són diferents de les formes que sorgeixen a mesura que el capital s'empara del control sobre el procés de producció. Les dones, que abans havien estat sotmeses al control dels seus matits dins la llar, si són treballadores assalariades esdevenen sotmeses al control capitalista. Així, esdevenen subjectes a la dominació dels seus marits dins la família i a la dominació del capital i els seus agents si també realitzen treball assalariat. Crec que cal esperar trobar que les formes de dominació i l'experiència que les dones en tenen siguin diferents en les diverses institucions, segons el paper de la institució en quiestió dins l'organització de l'economia capitalista en general, la forma de la seva organit. zació material i la forma de les relacions ideològiques $\mathrm{i}$ de poder que hi

7. Amb això vol dir que el marxisme no s'ha preocupat de les formes de dominació masculina i de subordinació femenina. 
són prevalents. Finaiment, em sembla que ens enfrontem amb una tasca difícil. ¿Com podem utilitzar un mètode materialista d'anàlisi de tal forma que puguem integtar satisfactòriament la producció i la reproducció com a part d'un procés únic, i que reveli que les diferenciacions de gènere són inseparables de la forma de l'organització de l'estructura de classe? 



\section{REFERENCIES}

Althusser, Louis, For Marx (London: New Left Books, 1969).

Althusser, Louis, Reading Capital (London: New Left Books, 1970).

Althusser, Louis, Lenin and Pbilosopby and other Essays (London: New Left Books, 1971).

Barrett, Michèle, i McIntosh, Mary, "Christine Delphy: Towards a Materialist Feminism?», Feminist Review, núm. 1 (1979), pp. 95-105.

Bland, Lucy, Brunsdon, Charlotte, Hobson, Dorothy i Winship, Janice, "Women "Inside and Outside" the Relations of Production» a Women's Studies Group, Centre for Contentporary Cultural Studies (1978).

Campbeil, Beatrix i Charlton, Valerie, «Work to Rule» Red Rag (1978).

Delphy, Christine, The Main Enemy: A Materialist Analysis of Women's Opression (London: WRRC Publications), «Explorations in Feminism», núm. 3 (1977).

Edholm, Felicity, Hartis, Olivia, i Young, Kate, «Conceptualizing Women», Critique of Antbropology, 9 i 10, vol. 3 (1977).

Eisenstein, Zillah R. (ed.), Capitalist Patriarchv and the Case for Socialist Feminism (New York and London: Monthly Review Press, 1979).

EngeIs, Friedrich, "The Origin of the Family, Private Property and the State», Marx and Engels (1968).

Firestone, Shulamith, The Dialectic of Sex (New York: Bantam, 1971).

Freud, Sigmund, Totem and Taboo (London: Routledge and Kegan Paul, 1950).

Hanmet, Jalna, Lunn, Kathy, Jeffreys, Sheila, i McNeill, Sandza, «Sex Class - Why is it important to call women a class?», Scarlet Women, núm. 5.

Hartmann, Heidi, «Capitalism, Patriatchy and Job Segregation by Sex», a Eisenstein, 1979 (1979a).

Hartmann, Heidi (1979b), «The Unhappy Marriage of Marxism and Feminism», propera publicació a Capital and Class, núm. 8, 1979.

Hirst, Paul Q., "Althusser and the Theory of Ideology», Economy and Society, vol. 5, núrn. 4, novembte 1976. 
«Papers»: Revista de Sociologia

Jeffreys, Sheila, «The Need for Revolutionary Feminism», Scarlet Women, núm. 5.

Kuhn, Annette, i Wolpe, Marie (eds.), Feninism and Materialism (London: Routledge and Kegan Paul, 1978).

Levi-Strauss, Claude, The Elementary Structures of Kinsbip (London: Eyre \& Spottiswoode, 1969).

Marx, Karl, i Engels, Friedrich, Selected Works (un volum) (London: Law tence \& Wishart, 1968).

$m / f$, núms. 1 i 2 (1978).

MacKintosh, Maureen, «Reproduction and Patriarchy: A Critique of Meillassoux, "Femmes, Greniers et Capitaux"», a Capital and Class, núm. 2 (1977).

McDonough, Roisin, i Harrison, Rachel, «Patriarchy and Relations of Productions, a Kuhn i Wolpe (1978).

McKenzie, Finelia, «Feminism and Socialism», Scarlet Women, núm. 5.

Meillassoux, Claude, Femmes, Greniers et Capitaux (Paris: Maspero, 1975).

Millett, Kate, Sexual Politics (New York: Doubleday, 1969).

Mitchell, Juliet, Psycboanalisis and Feminism (London: Allen Lane, 1974).

O'Loughlin, Bridget, «Production and Reproduction: Meillassoux's, "Femmes, Greniers et Capitaux" ", Critique of Antbropology, vol. 2, núm. 8 (1977).

Page, Margaret, «Socialist Feminism - A Political Alternative?», $m / t$, núm. 2 (1978).

Reiter, Rayna R. (ed.), Toward an Antbropology of Women (New York: Monthly Review Press, 1975).

Rubin, Gayle, «The Traffic in Women: Notes on the Political Economy of Sex», a Reiter (1975).

Samuel, Raphael, «Workshop of the World, History Worksbop Journal, núm. 3, primavera 1977 .

Scarlet Women Collective, Scarlet Women, núm. 5 (sense data), North Shields Tyne and Wear.

Taylor, Barbara, "Our Labour and Our Power», Red Rag, núm. 10 (19751976).

Weber, Max, Economy and Society, vol. 3 (New York: Bedminster Press, 1968).

Women's Studies Group, Centre for Contemporary Cultural Studies, Women Take Issue (London: Hutchinson, 1978). 